\title{
Ethnic Differences in Thermal Responses between Thai and Japanese Females in Tropical Urban Climate
}

\author{
${\text { Yoshihito Kurazumi }{ }^{*} \text {, Jin Ishii }}^{2}$, Kenta Fukagawa ${ }^{3}$, Emi Kondo ${ }^{4}$, Ariya Aruninta ${ }^{5}$ \\ ${ }^{1}$ School of Life Studies, Sugiyama Jogakuen University, Nagoya, Japan \\ ${ }^{2}$ Faculty of Education, Gifu University, Gifu, Japan \\ ${ }^{3}$ Department of Architecture, Kyushu Sangyo University, Fukuoka, Japan \\ ${ }^{4}$ Department of Architecture, Ariake National College of Technology, Omuta, Japan \\ ${ }^{5}$ Department of Landscape Architecture, Chulalongkorn University, Bangkok, Thailand \\ Email: kurazumi@sugiyama-u.ac.jp
}

Received 31 October 2015; accepted 27 March 2016; published 30 March 2016

Copyright (C) 2016 by authors and Scientific Research Publishing Inc.

This work is licensed under the Creative Commons Attribution International License (CC BY).

http://creativecommons.org/licenses/by/4.0/

(c) (i) Open Access

\begin{abstract}
The outdoor thermal environment might become worse than at present. It causes health injuries through the deterioration of the outdoor thermal condition. It is necessary to study how humans stay outdoors and adjust to thermal conditions. The purpose of this study was to clarify the influence of the outdoor tropical urban thermal environment on a subject who has been acclimatized to the environment studied using the outdoor thermal environment evaluation index ETFe. In addition, the tendency of human impacts was clarified through comparison to subjects from a temperate thermal environment region. As a result, it was found that an ETFe of up to $35^{\circ} \mathrm{C}$ could be recognized as a temperate thermal environment. However, when the ETFe was greater than $40^{\circ} \mathrm{C}$, the subject could not tolerate the environment. There was not a significant difference of psychological reaction between Thai people, who were acclimatized to the tropical climate, and Japanese people, who were acclimatized to the temperate climate.
\end{abstract}

\section{Keywords}

ETFe, Temperate Zone, Thermal Environment, Thermal Sense, Tropical Zone

\section{Introduction}

In the fifth IPCC report, the IPCC Working Group I Contribution to AR5 [1] mentioned that the agreed size of ${ }^{*}$ Corresponding author.

How to cite this paper: Kurazumi, Y., Ishii, J., Fukagawa, K., Kondo, E. and Aruninta, A. (2016) Ethnic Differences in Thermal Responses between Thai and Japanese Females in Tropical Urban Climate. American Journal of Climate Change, 5, 52-68. http://dx.doi.org/10.4236/ajcc.2016.51007 
the reduction of carbon dioxide emissions is insufficient to stop the rise of global temperature. The goal of the international agreement to avoid the severe effects of climate change is to limit the temperature rise to a maximum of $2^{\circ} \mathrm{C}$ compared to the temperature before the Industrial Revolution. However, under the present conditions, the temperature increase is likely to be about $3^{\circ} \mathrm{C}$. With no effective countermeasures, the average temperature increase will be between $3.7^{\circ} \mathrm{C}$ and $4.8^{\circ} \mathrm{C}$ and will cause a negative outdoor thermal environment. The moderate climate area changes to tropical one and ways to stay in outdoor spaces might need to be reconsidered.

A harsh thermal environment can be beyond the thermoregulatory capability of the human body. A high thermoregulatory load potentially causes a serious health hazard. In order to prevent health hazards, it is essential to demonstrate the impact of thermoregulatory loads on the human body. The sensations of hot/cold and of thermal comfort with respect to thermal environmental stimuli are important triggers for behavioral thermoregulation (i.e. environmental evacuation behavior) taken to improve the thermal environment from harsh to comfortable. A decline in the independent thermoregulatory function leads to a change in body core temperature. A delayed or weak thermal sensory response to heat or heat stroke results in delayed environmental evacuation behavior.

People travel across the globe, and travel time has become exceedingly short. Inevitably, people cannot adapt to the thermal environment of the region to which they move and cannot help but undergo thermal environment stimulation. Accordingly, with respect to the thermal environment stimuli, it is important to understand the difference in the physical impact on a person who has just moved to an area and on a person resident in the area.

Edwards et al. [2] and Watson et al. [3] investigate differences in the skin's pain sensation in response to heat stimuli. A field survey by Edwards et al. [2] concludes that there is no scientific basis to indicate clearly an ethnic difference in the skin's heat pain sensation, but Watson et al. [3] find that Asians from tropical regions have a lower skin heat pain sensory threshold with respect to heat stimuli than Caucasians from the cold region of the UK.

Taylor [4] and Saat and Tochihara [5] investigate differences in heat acclimatization. A field survey by Taylor [4] finds no scientific basis clearly indicating an ethnic difference, but Saat and Tochihara [5] find the skin temperatures and rectal temperatures of Thai and Malaysian inhabitants of tropical regions higher and heart and perspiration rates lower than those of the Japanese.

Lee et al. [6] [7], Wijayanto et al. [8], and Wakabayashi et al. [9] investigate differences in the physiological response to heat stimuli. Lee et al. [6] find that Malaysian men from tropical regions have a higher temperature threshold at which warmth is detected compared to Japanese men from a temperate region. They find that the most remarkable ethnic difference is in the forehead, and suggest the possibility that Malaysians can tolerate a higher temperature than the Japanese. Lee et al. [7] find that the temperature of the extremities of Malaysians becomes higher and the core temperature slightly lower compared to those of the Japanese under a strong heat stimulus. They suggest that Malaysians have a strong ability for stabilizing core temperature. Wijayanto et al. [8] do not observe any difference in perspiration volume or average skin temperature between Malaysian men residing in a tropical region and Japanese men residing in a temperate region, but find the hand skin temperature of Malaysian men higher than that of Japanese men. Wakabayashi et al. [9] do not observe any difference in perspiration volume between adult Malaysian men from a tropical region and adult Japanese men from a temperate region when under exercise stress, but find the rectal temperature and skin temperature of Japanese men higher than Malaysian men in this condition.

Tochihara et al. [10] conduct a questionnaire on the expression of heat sensation. They find that "cool" and "slightly cool" are within the range of thermal comfort for Indonesians from a tropical region but "slightly warm" and "warm" are also within the range of thermal comfort for Japanese people from a temperate region. In the survey, "hot" was frequently reported to be in excess of $32^{\circ} \mathrm{C}$ for Indonesians and $29^{\circ} \mathrm{C}$ for the Japanese. "Cold" was frequently reported as being under $20^{\circ} \mathrm{C}$ for Indonesians and $15^{\circ} \mathrm{C}$ for the Japanese.

Kurazumi et al. [11] investigate an outdoor thermal environment and its effect on the human body by means of an outdoor thermal environmental evaluation index ETFe. They demonstrate that Thai people from a tropical region perceive an ETFe of up to around $35^{\circ} \mathrm{C}$ to be a moderate thermal environment but cannot tolerate an environment with an ETFe in excess of around $40^{\circ} \mathrm{C}$. Compared to the results of research by Kurazumi et al. [12] for Japanese people from a temperate region, they observed the tendency that Thai people from a tropical region prefer a slightly cool thermal environment but found no great difference in heat sensation with respect to hot stimuli.

Concerning the physiological response to heat stimuli, the above discussion implies that ethnic groups resid- 
ing in tropical regions have a strong resistance to the stimuli in comparison to ethnic groups from other regions. Only Tochihara et al. [10] and Kurazumi et al. [11] investigate physiological response with respect to heat stimuli. In addition, Kurazumi et al. [11] is the only study to investigate ethnic differences in the effect of heat stimuli on the human body using thermal environmental evaluation index as an evaluation scale. However, there is currently no research on test subjects in the same thermal environment investigating ethnic differences in the thermal sensation of the human body using a thermal environmental evaluation index.

In outdoor spaces in summer, when the sunlight gets stronger people feel hotter, when the wind gets stronger people feel cooler, and when the humidity gets higher people feel hot and humid. In addition, roads become very hot and very difficult to touch by hand. For that reason, it is necessary to take into consideration environmental factors, such as thermal radiation, convection, humidity, and heat conduction to estimate the human thermal sensation.

Givoni et al. [13], Oliveira and Andrade [14], Eliasson et al. [15], Nikolopoulou and Steemers [16], Nikolopoulou and Lykoudis [17], and Ishii et al. [18] studied the relationship between physical environmental factors and human thermal sensation. These studies clarified that the temperature, wind direction, and solar radiation affect the thermal sensation of humans. Kurazumi et al. [19] studied outdoor environmental factors and showed that heat conduction, humidity, and short-wave solar radiation affect the thermal sensation of humans. Kurazumi et al. [20] showed that temperature, humidity, wind flow, long-wave thermal radiation, short-wave solar radiation, and heat conduction affect the thermal sensation and thermal comfort of humans in winter.

When the thermal environment is under heated conditions, short-wave solar radiation shows a strong influence on the human body and the heat is accumulated in the human body. This raises the risk of heat stroke. When the air temperature is higher than skin temperature, perspiration is the only way for heat release to occur. However, when the humidity gets higher, it reduces the amount of perspiration from the human body. Shortwave solar radiation and long-wave thermal radiation from the ground raise the thermal sensation. For that reason, the deterioration of the outdoor thermal environment due to the heat island phenomenon probably causes a health hazard [21]. Sunlight shading is an effective way to decrease the influence of short-wave solar radiation. For long-wave thermal radiation, ground cover and water spaces are effective. Therefore, it is important to study methods of lowering the outdoor temperature.

Humphreys [22], Brager and deDear [23], de Dear and Brager [24], Nikolopoulou et al. [25], Nikolopoulou and Steemers [16], Knez and Thorsson [26], Nikolopoulou and Lykoudis [17], Kántor and Unger [27], and Kurazumi et al. [28] mentioned that in outdoor spaces, not only physical and physiological environmental impacts but also psychological environmental impacts affect thermal comfort. In addition, it is also mentioned that based on the thermal environment history, such as cultural background and the experience of hot and cold environments, the expectation of the thermal environment, active body heat control, and exposure time affect the adaptation to the thermal environment. The research target included not only the thermal comfort but also the space impression as comprehensive comfort. On the other hand, Kurazumi et al. [12] [19] [20] [29] clarified that there is a correlation between thermal sensation, thermal comfort, and ETFe by using ETFe, which is an index for evaluating the outdoor thermal environment [30].

Höppe [31], Nikolopoulou and Steemers [16], Spagnolo and de Dear [32], Nakano and Tanabe [33], Ahmed [34], Oliveira and Andrade [14], Lin and Matzarakis [35], Cheng et al. [36], and Kurazumi et al. [12] [29] mentioned that outdoor thermal comfort is different to thermal comfort in the indoor environment due to environmental adaptability. In winter, the preferred temperature is lower than in summer, and in summer the accepted temperature is higher than in winter. The thermal comfort range is wider outdoors than indoors.

These previous studies have mentioned that the thermal sense changes by adaptation to the thermal environment. Although the thermal sense is the subject of this research, it is treated as an evaluation of a comprehensive impression of space caused by environmental stimuli other than thermal stimuli. In addition, there is not enough research using a total thermal environment evaluation index based on the heat balance. Taking into account the average global air temperature rise, it is important to study the effect of the outdoor thermal environment in tropical regions on humans.

For that reason, we have targeted the effect of the outdoor thermal environment on humans who are adjusted to the environment by carrying out experiments on subjects and by using the outdoor thermal environment evaluation index ETFe [30]. In addition, the difference in the effect on human body between subjects from a temperate thermal environment region and a tropical region was investigated.

It is rare to perform a subjective experiment that measures physiological and psychological quantities accord- 
ing to the response of the human body using a large number of subjects. It is difficult to perform an experiment that is hypothesized on a statistical population. Accordingly, as only a small number of subjects was used in this study, the new data are a significant addition to the literature.

\section{Experimental Design}

\subsection{ETFe}

The sensational and physiological climatic environment index ETFe [12] [19] [20] [29] [30] converts the effects of the following parameters into a temperature-equivalent value: change in posture, air velocity, long-wave radiation in outdoor space, short-wave solar radiation, contact material surface temperature, and humidity.

The influence of the 5 environmental factors in relation to the heat balance of the human body can be expressed by the newly defined thermal environment evaluation indices of 1 ) heat transfer area combined with the thermal velocity field $\left(\mathrm{TVF}_{\mathrm{hta}}\right)$, which concerns air velocity, 2) radiant heat transfer area combined with the effective radiation field concerning long-wave radiation in outdoor spaces $\left(\mathrm{ERF}_{\mathrm{htaL}}\right)$, 3) radiant heat transfer area combined with the effective radiation field concerning short-wave solar radiation in outdoor spaces $\left.\left(E F_{h t a s}\right), 4\right)$ heat transfer area combined with the effective conduction field $\left(\mathrm{ECF}_{\mathrm{hta}}\right.$ ), which concerns the surface temperature of the part which is contacted, and 5) the effective humidity field at the enhanced conduction-corrected modified effective temperature $\left(\mathrm{EHF}_{\mathrm{ETF}}\right.$ ), which concerns humidity. Therefore, the addition of each temperature-converted factor is possible and the composite effect of the sensational and physiological temperature in outdoor spaces, as well as the discrete effect of each meteorological element, is quantified.

$$
\begin{aligned}
& \mathrm{ETFe}=T_{a}+\frac{\mathrm{TVF}_{\text {hta }}}{h_{f L}}+\frac{\mathrm{ERF}_{\text {hta }}}{h_{f L}}+\frac{\mathrm{ECF}_{\text {htaL }}}{h_{f L}}+\frac{\mathrm{EHF}_{\mathrm{ETFe}}}{h_{f L}}+\frac{\mathrm{ERF}_{\text {htas }}}{h_{f L}} \\
& \operatorname{TVF}_{\text {hta }}\left(h_{o} f \text { cl Fclo } f_{\text {conv }}-h_{v} f \text { clFcl } f_{\text {conv }}\right)\left(t_{s}-t_{a}\right) \\
& \mathrm{ERF}_{\mathrm{htaL}}=h_{r L} f_{c l} \text { FCl } f_{r a d}\left(t_{r L}-t_{a}\right) \\
& \mathrm{ECF}_{\text {hta }}=h_{d} \text { Fcld } f_{\text {cond }}\left(t_{f}-t_{a}\right) \\
& \mathrm{EHF}_{\mathrm{ETFe}}=L w h_{c} f c l F p c l\left(p_{a}-0.5 p_{\mathrm{ETFe}}^{*}\right) \\
& \mathrm{ERF}_{\text {htas }}=R_{s} \\
& h_{f L}=h_{o} \text { fclFclo } f_{\text {conv }}+h_{r L} f c l F c l f_{\text {rad }}+h_{d} \text { Fcld } f_{\text {cond }}
\end{aligned}
$$

where

ETFe: enhanced conduction-corrected modified effective temperature [K];

$T_{a}$ : air temperature $[\mathrm{K}]$;

$\mathrm{TVF}_{\mathrm{hta}}$ : convective heat transfer area of the combined with thermal velocity field $\left[\mathrm{W} / \mathrm{m}^{2}\right]$;

$E R F_{\text {htaL }}$ : radiant heat transfer area combined with the effective radiation field concerning the long-wave radiation in outdoor space $\left[\mathrm{W} / \mathrm{m}^{2}\right]$;

$E F_{h t a s}$ : radiant heat transfer area combined with the effective radiation field concerning the short-wave solar radiation in outdoor space $\left[\mathrm{W} / \mathrm{m}^{2}\right]$;

$\mathrm{ECF}_{\mathrm{hta}}$ : heat transfer area combined with effective conduction field $\left[\mathrm{W} / \mathrm{m}^{2}\right]$;

$\mathrm{EHF}_{\mathrm{ETFe}}$ : effective humidity field at enhanced conduction-corrected modified effective temperature $\left[\mathrm{W} / \mathrm{m}^{2}\right]$;

$h_{r L}$ : radiant heat transfer coefficient concerning the long-wave radiation in outdoor space $\left[\mathrm{W} / \mathrm{m}^{2} \mathrm{~K}\right]$;

fcl: effective surface area of clothing [-];

$f_{\text {conv: }}$ convective heat transfer area factor $[-]$;

$f_{\text {cond: }}$ : conductive heat transfer area factor [-];

$f_{\text {rad }}$ : radiant heat transfer area factor [-];

Fcl: thermal efficiency factor of clothing [-];

Fcld: thermal efficiency factor of clothing [-];

Fclo: thermal efficiency factor of clothing under the standard condition [-];

Fpcl: permeation efficiency factor of clothing [-]; 
$h_{c}$ : convective heat transfer coefficient $\left[\mathrm{W} / \mathrm{m}^{2} \mathrm{~K}\right]$;

$h_{d}$ : resultant heat conductance $\left[\mathrm{W} / \mathrm{m}^{2} \mathrm{~K}\right]$;

$h_{f \mathrm{~L}}$ : sensible heat transfer coefficient in outdoor space $\left[\mathrm{W} / \mathrm{m}^{2} \mathrm{~K}\right]$;

$h_{o}$ : convective heat transfer coefficient under the standard condition $\left[\mathrm{W} / \mathrm{m}^{2} \mathrm{~K}\right]$;

$L$ : Lewis relation coefficient $[\mathrm{K} / \mathrm{kPa}]$;

$p_{a}$ : water vapor pressure at the outdoor air temperature $[\mathrm{kPa}]$;

$p_{\mathrm{ETFe}}^{*}$ : saturated water vapor pressure at enhanced conduction-corrected modified effective temperature $[\mathrm{kPa}]$;

$R_{S}$ : short-wave solar radiation heat gain of human body $\left[\mathrm{W} / \mathrm{m}^{2}\right]$;

$T_{s}$ : convection-corrected mean skin temperature [K];

$T_{f}$ : surface temperature of the contacted material $[\mathrm{K}]$;

$T_{r L}$ : mean radiant temperature concerning long-wave radiation in outdoor space [K];

$w$ : skin wettedness [-].

\subsection{Measurement Procedure}

The measurements were carried out in September in the Thai rainy season. Mobile measurements were carried out on the campus of Chulalongkorn University, Bangkok, Thailand. A speed of movement slower than a normal walking speed of around $0.7 \mathrm{~m} / \mathrm{s}$ was used to transport the instruments for measuring the thermal environment. The observation points were drawn at random and the routes to the points were not decided in advance. With consideration to the burden on subjects, physical strength, and mental fatigue, the experiments were concluded two hours after commencement of the mobile observations.

In indoor spaces such as a laboratory, it is exceedingly rare to test subjects in extremely hot or cold thermal environments. In general in experiments that include a transition period or an uneven thermal environment, the time period of the exposure experiment is the subject of the investigation, so that the heat balance between the human body and the environment becomes almost a steady state. However, the thermal environment of outdoor spaces in summer can be harsh to the extent that there are cases of deaths due to heatstroke, whilst that of winter outdoor spaces can be harsh to the extent that the body temperature drops to the zone of hypothermia. Accordingly, one must avoid extended periods in outdoor spaces where one would be struck by direct solar radiation in a high-temperature environment. It is unavoidable for experiments on subjects in outdoor spaces to include a short transition period. Thus, taking into consideration the subjects' maintenance of a standing posture and the response time of the Assman ventilated psychrometer, the actual measurements of the human body response and thermal environment in the mobile observations were performed after having set up the observation device and left it for 10 minutes. Naturally, it can be conjectured that the longer the exposure time of the subjects, the more the response of the human body will differ, and the experimental period was determined with consideration of the safety of the subjects. Unlike in an indoor space, it is difficult to consider spending extended periods in an outdoor thermal environment that can be considered uncomfortable due to behavioral thermoregulation by means of refuge behavior from environmental stress.

As mentioned in the Introduction, adaptation to the thermal environment according to the influence of thermal environment history is apparent [16] [17] [22] [24]-[27], but a research method that removes the influence of environment history to the greatest possible extent was used in this study, similar to Kurazumi et al. [12]. Subjects moved on foot to the observation point after sitting and being at rest at the control observation point 0 . While they were seated and at rest, the subjects were informed that psychological reporting involves a thermally specific senses, that they would be asked to report the average sensation during the period of exposure, and that intake and excretion of liquids were prohibited until the conclusion of the experiment. The speed of movement of the subjects was slower than a normal walking speed of around $0.7 \mathrm{~m} / \mathrm{s}$, as detailed above, because of the movement of the trolley in which the research staff transported the measurement instruments.

After arriving at each measurement point, the subjects waited in a standing posture for 5 minutes while the test staff set up the measurement instruments for the thermal environment, and preparations for measurement were concluded. Thereafter, the subjects were exposed to the thermal environment in a standing posture for 10 minutes, as shown above. The subjects were positioned around the thermal environment measurement instruments in a location where they did not obstruct the sunlight, and they surrounded the thermal environment measurement instruments. As the subject of the research was the environment surrounding the observation stations, 
the point of gaze of the subjects was free and unfixed. After 10 minutes' exposure, the subjects reported the average thermal sensation and the average thermal comfort of the whole body that they experienced while exposed at the observation point.

\subsection{Outline of the Observation Points}

A summary of the observation points is shown in Table 1. For the measurements, observation points were selected with consideration of the condition of the ground surface such as bare ground, where the surface is gravel or soil, paved ground such as concrete, asphalt, or blocks, green areas covered with plants, and water surfaces comprising the solid angle of the total celestial sphere (hereafter, green factor), and with consideration of the condition of the sky factor due to buildings, trees, and so on. Five observation points were chosen.

\subsection{Subjects}

The subjects were 17 healthy females. The height of the 10 Thai females was $1.599 \pm 0.100 \mathrm{~m}$ and their weight was $51.7 \pm 10.0 \mathrm{~kg}$. The height of the 7 Japanese females was $1.574 \pm 0.057 \mathrm{~m}$ and their weight was $50.0 \pm 7.0$ $\mathrm{kg}$. Thus, they were considered to be good subjects by most physical standards.

In accordance with the Declaration of Helsinki [37], the details of the experiment were explained sufficiently well in advance to the subjects and their consent was obtained for their voluntary participation.

\subsection{Measured Parameters}

Air temperature, humidity, air velocity, short-wave solar radiation heat quantity, long-wave radiation heat quantity, ground surface temperature, and water surface temperature were measured. The air temperature and humidity were measured at a height of $0.9 \mathrm{~m}$ above the ground by means of an Assmann ventilated psychrometer. The average air velocity was measured for 5 minutes at a height of $0.9 \mathrm{~m}$ above the ground by an omnidirectional anemometer (Kanomax Japan: 6533; measurement range: $0.05-5.00 \mathrm{~m} / \mathrm{s}$ ). Concerning the short-wave thermal radiation heat quantity in the visible to near- and mid-infrared regions and the terrestrial thermal radiation in the far infrared region, thermal radiation heat quantities in the downwards and upwards directions were measured at a height of $0.9 \mathrm{~m}$ above the ground by a long-wave and short-wave radiometer (Climatec: CHF-NR01; sensitivity: $10 \mathrm{mV} /\left(\mathrm{kWm}^{-2}\right)$, short-wave range: 285 - $3000 \mathrm{~nm}$; long-wave range: 4500 - 40,000 nm). The ground surface temperature in the vicinity of the human body was measured by a radiation thermometer (Nippon Avionics: F30S; measurement wavelength: $8-14 \mu \mathrm{m}$; measurement range: $-20^{\circ} \mathrm{C}-100^{\circ} \mathrm{C}$; sensitivity: $0.1^{\circ} \mathrm{C}$ ). The sky factor was measured by a photograph of the sky taken $0.9 \mathrm{~m}$ above the ground at the observation point using a fisheye lens with an orthographic projection format (Yasuhara: Madoka $1807.3 \mathrm{~mm} \mathrm{f} / 4$ ) and a $35 \mathrm{~mm}$ digital

Table 1. Summary of observation points.

\begin{tabular}{|c|c|c|c|c|c|c|c|c|c|c|}
\hline Point & Survey site & $\begin{array}{l}\text { Ground } \\
\text { surface }\end{array}$ & $\begin{array}{l}\text { Skywards } \\
\text { surface }\end{array}$ & $\begin{array}{l}\text { Surrounds } \\
\text { North } \\
\text { side }\end{array}$ & $\begin{array}{l}\text { Surrounds } \\
\text { East side }\end{array}$ & $\begin{array}{l}\text { Surrounds } \\
\text { South } \\
\text { side }\end{array}$ & $\begin{array}{l}\text { Surrounds } \\
\text { West side }\end{array}$ & $\begin{array}{l}\text { Sky } \\
\text { factor }\end{array}$ & $\begin{array}{l}\text { U-green } \\
\text { factor }\end{array}$ & $\begin{array}{l}\text { D-green } \\
\text { factor }\end{array}$ \\
\hline 0 & $\begin{array}{l}\text { Building } \\
\text { canyon }\end{array}$ & Concrete & Eaves & Building & Building & Building & Building & 0.142 & 0.340 & 0.005 \\
\hline 1 & Pond side & $\begin{array}{l}\text { Grass \& } \\
\text { Pond }\end{array}$ & Tree & Open & Open & Tree & Tree & 0.255 & 0.659 & 0.763 \\
\hline 2 & Playground & $\begin{array}{l}\text { Grass \& } \\
\text { Bare } \\
\text { ground }\end{array}$ & Open & Open & Open & Open & Open & 0.875 & 0.091 & 0.814 \\
\hline 3 & $\begin{array}{l}\text { Building } \\
\text { side's bower }\end{array}$ & Concrete & $\begin{array}{l}\text { Sunshade } \\
\text { \& Tree }\end{array}$ & Open & Building & Tree & Building & 0.165 & 0.560 & 0.073 \\
\hline 4 & Open space & Concrete & Open & Building & Open & Open & Open & 0.414 & 0.362 & 0.173 \\
\hline
\end{tabular}

Sky factor is defined as the ratio of configuration factor of sky to semi celestial sphere. U-green factor is defined as the ratio of upward green, water surface and the like solid angles to semi celestial sphere solid angle. D-green factor is defined as the ratio of downward green, water surface and the like solid angles to semi celestial sphere solid angle. 
SLR camera (Sony: $\alpha 7$ ). The ratio of green and water surface solid angles to the celestial globe solid angle was calculated by a converted photograph of equisolid angle projection format from a photograph in orthographic projection format. The albedo, sky temperature, and ground surface temperature were calculated from each directional component of the short-wave thermal radiation heat quantity and the long-wave thermal radiation heat quantity. Moreover, it is indispensable for the surrounding ground surface temperature to calculate the heat conduction. The ground surface temperature in the vicinity of the human body was measured by a radiation thermometer. For the calculation of the long-wave thermal radiation heat quantity, the sky and ground surface temperatures were used.

The skin temperature was measured at the positions of the head, trunk, arm, hand, thigh, lower leg, and foot. The skin temperature was measured as the physiological condition of the human body by a thermistor thermometer (Nikkiso-Thermo, N542R and ITP8391; measurement range: $-50^{\circ} \mathrm{C}-230^{\circ} \mathrm{C}$; resolution: $0.01^{\circ} \mathrm{C}$ ). The subjects freely selected their clothing to be suitable for the weather on the measurement day. The quantity of clothing of the subjects was evaluated by the "clo" value by composite ensemble method for layering the clothing reported by the subjects [38]. With regard to the psychological condition of the human body, the psychological response was measured after staying at the observation point for 10 minutes by means of rating the whole-body thermal sensation (seven grades) and whole body thermal comfort (in 5 grades).

ETFe is an outdoor thermal environment evaluation index based on the heat balance of the human body. Accordingly, the calculation of the mean skin temperature used for the calculation of the heat balance of the human body was performed using a weighting coefficient that takes into account the convective heat transfer area [39]. Then, the calculation of the mean skin temperature used for the physiological response of the human body was performed using a weighting coefficient that takes into account heat conduction [40]. The values of Kurazumi et al. [41] were used for the convective heat transfer area factor, the radiant heat transfer area factor, and the conduction heat transfer area factor for the human body. The value of Miyamoto et al. [42] was used for the projection area ratio of the human body. The values of Kuwabara et al. [43] were used for the radiant heat transfer coefficient and convective heat transfer coefficient of the human body. The value of Hendler et al. [44] found from the reflectance by the skin of electromagnetic waves with wavelengths of $3 \mu \mathrm{m}$ or more was used for the emissivity of the human body. The value of Hendler et al. [44] and Elam et al. [45] found from the reflectance by skin of electromagnetic waves with wavelengths of $3 \mu \mathrm{m}$ or less was used for the solar radiation absorption coefficient of the human body. The short-wave solar radiation heat gain of human body is affected to the shortwave solar radiation absorption. According to VDI3787-2 [46], the direct solar radiation absorption of a clothed body is 0.7. However, Watanabe et al. [47] showed that the direct solar radiation absorption of a body clothed in black is 0.76 and that of a body clothed in white is 0.38 . Also, the direct solar radiation absorption of other clothing combinations or everyday clothing falls within the range of direct solar radiation absorption for a body in black or white clothing. In this study, a value for the short-wave solar radiation absorption of 0.7, which is standard for a naked body, was used. It was difficult to measure the skin wetness. Therefore, the calculation method used to arrive at these values of the skin wetness was the thermoregulation model of Kurazumi et al. [48]. The standard air velocity was considered to be $0.1 \mathrm{~m} / \mathrm{s}$ and the standard clothing was considered to be a naked body (0clo). The ETFe index theoretically proposed by Kurazumi et al. [19] [30] was calculated from weather observation values, the skin temperature of the human body, and the clothing value.

The statistical tests used the JMP statistical package. The statistical analyses were carried out with a significance level of 0.05 .

\section{Results}

\subsection{Observed Weather Summary}

Table 2 shows the results of weather measurements of the observation points. There are the observation points that the air temperature was under $30^{\circ} \mathrm{C}$. The September Bangkok climate is around the end of the rainy season. Through the year, this season has a relatively low temperature. Although there is much downward short-wave solar radiation at observation points in the open and with a high sky factor, the downward short-wave solar radiation at the observation points with low sky factors, such as wooded areas in which sunlight is blocked, is remarkably low. The results of direct sunlight were clearly observed.

The amount of long-wave thermal radiation is remarkably high at each observation point. Even when people take refuge from short-wave solar radiation by moving to shaded areas out of direct sunlight, a large amount of 
Table 2. Results of field survey.

\begin{tabular}{|c|c|c|c|c|c|c|c|c|c|c|}
\hline Date & Time & Point & $\begin{array}{c}\mathrm{Ta} \\
{\left[{ }^{\circ} \mathrm{C}\right]}\end{array}$ & $\begin{array}{c}\mathrm{Tf} \\
{\left[{ }^{\circ} \mathrm{C}\right]}\end{array}$ & $\begin{array}{l}\text { RH } \\
{[\%]}\end{array}$ & $\begin{array}{c}\mathrm{Va} \\
{[\mathrm{m} / \mathrm{s}]}\end{array}$ & $\begin{array}{l}\text { RSdwn } \\
{\left[\mathrm{W} / \mathrm{m}^{2}\right]}\end{array}$ & $\underset{\left[\mathrm{WS} / \mathrm{m}^{2}\right]}{\mathrm{Rup}}$ & $\begin{array}{l}\text { RLdwn } \\
{\left[\mathrm{W} / \mathrm{m}^{2}\right]}\end{array}$ & $\begin{array}{c}\text { RLup } \\
{\left[\mathrm{W} / \mathrm{m}^{2}\right.}\end{array}$ \\
\hline 16 Sept. & $10: 33$ & 0 & 31.1 & 28.7 & 57.1 & 1.05 & 13.27 & 1.93 & 482.68 & 469.84 \\
\hline 16 Sept. & $10: 54$ & 1 & 31.4 & 30.8 & 57.4 & 0.70 & 121.19 & 29.20 & 485.55 & 485.07 \\
\hline 16 Sept. & $11: 14$ & 2 & 32.5 & 38.7 & 54.5 & 2.02 & 549.48 & 95.03 & 455.59 & 516.58 \\
\hline 16 Sept. & 11:33 & 3 & 31.4 & 30.4 & 56.8 & 0.93 & 21.49 & 0.00 & 486.96 & 480.64 \\
\hline 16 Sept. & $11: 49$ & 4 & 32.5 & 37.1 & 55.5 & 1.44 & 569.60 & 132.96 & 466.02 & 514.84 \\
\hline 16 Sept. & $12: 11$ & 0 & 31.6 & 20.0 & 55.3 & 0.62 & 12.67 & 0.00 & 489.77 & 476.94 \\
\hline 16 Sept. & $13: 36$ & 0 & 32.2 & 29.5 & 53.7 & 0.75 & 6.11 & 0.00 & 488.34 & 476.03 \\
\hline 16 Sept. & $13: 56$ & 4 & 31.8 & 41.3 & 62.1 & 1.31 & 208.24 & 57.08 & 477.30 & 522.59 \\
\hline 16 Sept. & $14: 12$ & 3 & 30.7 & 31.0 & 65.4 & 0.84 & 8.28 & 0.00 & 484.16 & 482.48 \\
\hline 16 Sept. & $14: 41$ & 2 & 31.2 & 34.7 & 62.8 & 1.49 & 339.08 & 60.43 & 455.71 & 500.82 \\
\hline 16 Sept. & $14: 55$ & 1 & 31.2 & 30.6 & 64.0 & 0.57 & 49.47 & 10.58 & 484.49 & 480.98 \\
\hline 16 Sept. & $15: 12$ & 0 & 30.8 & 28.5 & 63.7 & 0.87 & 2.56 & 0.00 & 484.75 & 476.34 \\
\hline 17 Sept. & $9: 43$ & 0 & 29.4 & 26.2 & 63.9 & 0.80 & 9.78 & 1.54 & 473.98 & 466.35 \\
\hline 17 Sept. & $10: 01$ & 4 & 30.4 & 36.2 & 61.1 & 0.82 & 371.60 & 88.62 & 464.96 & 494.73 \\
\hline 17 Sept. & $10: 17$ & 3 & 29.8 & 29.3 & 61.8 & 0.93 & 25.62 & 0.57 & 476.51 & 473.49 \\
\hline 17 Sept. & $10: 34$ & 2 & 30.4 & 35.3 & 57.7 & 1.75 & 526.72 & 88.73 & 443.95 & 496.35 \\
\hline 17 Sept. & $10: 50$ & 1 & 30.0 & 29.1 & 60.8 & 0.60 & 69.63 & 12.68 & 476.55 & 475.52 \\
\hline 17 Sept. & $11: 07$ & 0 & 30.2 & 27.2 & 57.5 & 0.86 & 7.38 & 0.00 & 479.36 & 470.65 \\
\hline 17 Sept. & $12: 54$ & 0 & 30.5 & 29.2 & 61.8 & 0.56 & 15.63 & 3.07 & 479.31 & 471.52 \\
\hline 17 Sept. & $13: 12$ & 1 & 30.6 & 29.2 & 63.6 & 0.85 & 89.34 & 19.29 & 480.09 & 477.77 \\
\hline 17 Sept. & $13: 27$ & 2 & 32.0 & 40.8 & 58.9 & 1.25 & 910.18 & 143.49 & 449.42 & 524.54 \\
\hline 17 Sept. & $13: 44$ & 3 & 30.2 & 30.9 & 64.5 & 0.63 & 18.31 & 0.00 & 482.48 & 481.66 \\
\hline 17 Sept. & $13: 59$ & 4 & 30.8 & 40.2 & 59.1 & 1.30 & 337.03 & 86.61 & 462.60 & 515.14 \\
\hline 17 Sept. & $14: 19$ & 0 & 30.5 & 28.3 & 61.8 & 0.87 & 10.92 & 0.00 & 483.93 & 475.30 \\
\hline
\end{tabular}

Ta is range of air temperature. Tf is range of ground surface temperature in the vicinity of the human body. RH is relative humidity. Va is air velocity. RSdwn is downward short wave solar radiation. RSup is upward short wave solar radiation. RLdwn is downward long wave radiation. RLup is upward long wave radiation.

thermal radiation will be received. At observation points strongly influenced by short-wave solar radiation such as concrete paving, which has a high heat capacity, the daytime surface temperatures in the vicinity of the observation point, compared with other observation points, were remarkably high. At the observation points 2 and 4 that were affected the short-wave solar radiation, the ground surface temperature was over $40^{\circ} \mathrm{C}$. For example, the contact surface area between a standing person and the ground is small, yet due to heat conduction the heat received by the person is inferred to be strongly influenced by the contact skin temperature. Additionally, a high surface temperature in the vicinity of the person is inferred to strongly influence the amount of thermal radiation due to a high angle factor.

With an average value of relative humidity of $60.0 \%$ and a standard deviation of $3.4 \%$, no remarkable differences in measured results were shown. Therefore, the difference in evaporative heat loss is thought to weakly influence the sensational and physiological body temperature.

The average wind speed at all measurement points was comparatively low at less than $2 \mathrm{~m} / \mathrm{s}$ and had a standard deviation of $0.4 \mathrm{~m} / \mathrm{s}$; no remarkable differences in measured results were shown. Therefore the difference in convective heat exchange is thought to weakly influence the sensational and physiological body temperature. The wind speed of the observation points 2 and 4, which have more short-wave solar radiation within an opened 
space, were higher than the observation points 0 and 3, which are surrounded by buildings in a canyon-like space. The thermal sense is influenced by the wind speed that is a variation factor in the environment.

Kuwasawa et al. [49] reported a reduced rate of response of discomfort even in thermal environments responded to be hot due to the effects of varying airflow rather than constant airflow. Oliveira and Andrade [14] revealed that wind speed has the largest influence on comprehensive comfort. Also a trend showing that the effect of wind speed was a more negative factor for women than for men was revealed. Kurazumi et al. [19] [20] revealed that the influence of wind speed in both summer and winter was a variation factor that influenced the thermal sensation and thermal comfort of people in the outdoor thermal environment. Since the human body varies with environmental factors, an uncomfortable experience is possible, and that experience is considered to influence the relative comfort. Therefore, for other environmental factors, variations resulting from a reduced thermal effect are considered to be a variation factor for discomfort.

\subsection{Relationship between Thermal Sensation and Observation Point}

Figure 1 shows the relationship between thermal sensation and observation points. The "slightly warm" to "hot", for observation points 2 and 4 with a high sky factor, expressed as percentages that are remarkably high. Observation point 2 ground surface is covered with plants. Also, observation point 4 ground surface is almost covered

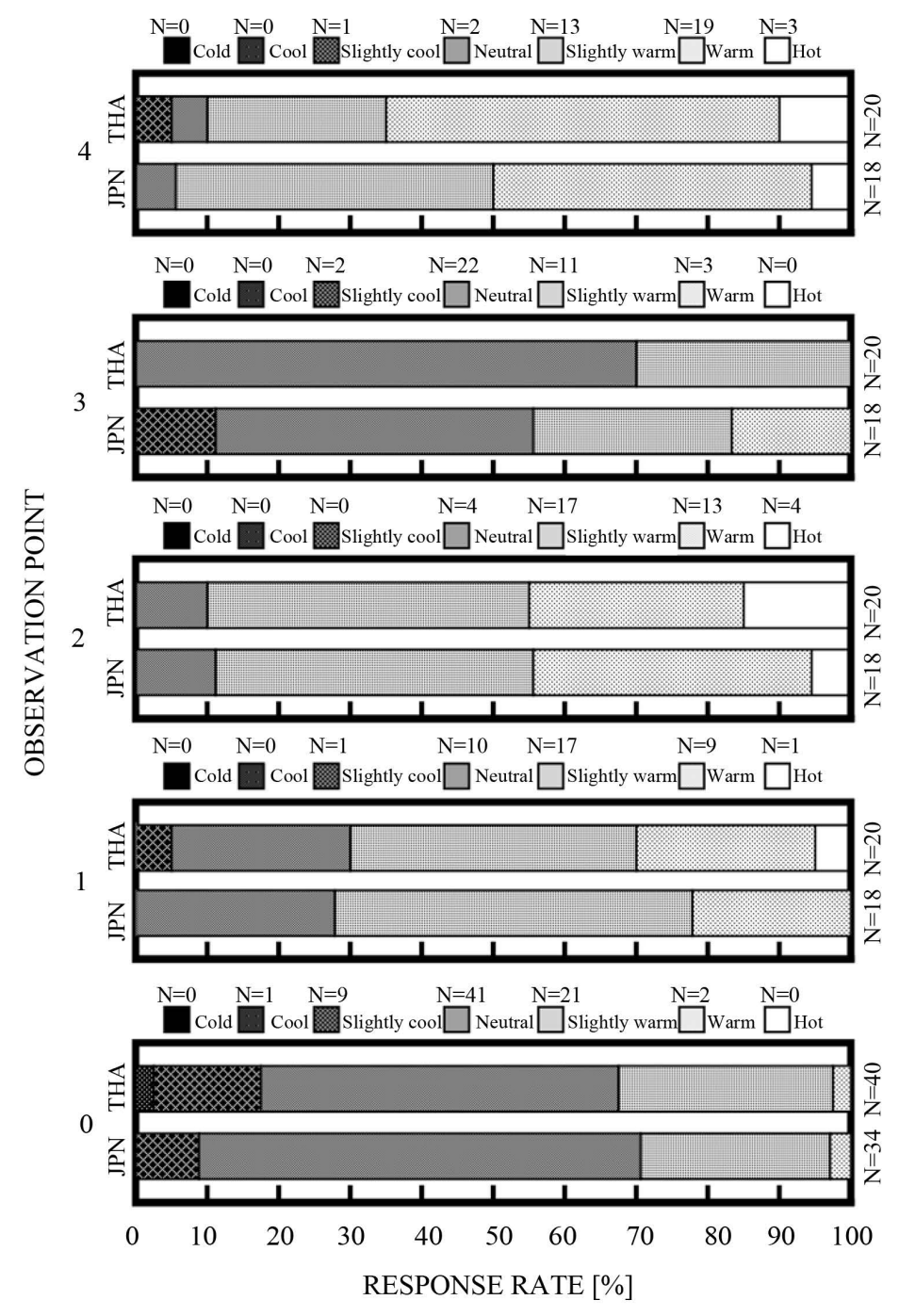

Figure 1. Relationship between thermal sensation and observation point. JPN is a Japanese female. THA is a Thai female. 
with concrete pavement. These observation points, which have the influence of the reflected sunlight, in spaces with nothing to block the sunlight, feelings of hot sensation are considered to be more apparent. On the other hand, the "neutral" to "cool" of observation points 0 and 3, which have a low sky factor, are expressed as percentages that are remarkably high. The observation point 1 , which has a high green factor, is expressed as a percentage that is intermediate response in the range from observation points 0 and 3 with a low sky factor to observation points 2 and 4 with a high sky factor. At observation points 0 and 3, which have a low sky factor, direct sunlight is almost blocked by buildings and trees. However, at the observation point 1 , sunlight filtering through the trees is considered to show an intermittent effect. Fukagawa et al. [50] show that visual stimuli created by water scenes serve to lower hot thermal sense by engendering a sense of depth. Kurazumi et al. [51] show that, in the indoor thermal environmental index ETF [52] deemed fairly uncomfortable, that is at a range of hotter than $28^{\circ} \mathrm{C}-29^{\circ} \mathrm{C}$, clear improvements were observed in thermal sense due to the influence of visual stimuli such as natural elements including vegetation like greenery. The visual stimuli of greenery and other factors served to ameliorate perceptions of high heat and high body temperature. At each observation point expressed as a responded percentage of thermal sensation that did not show a large difference between Thai females, who were acclimatized to the tropical region, and Japanese females, who were acclimatized to the temperate region.

The result of testing the homogeneity of responses was $p<0.01\left(\chi^{2}=140.31\right)$, showing a significant difference. Especially, observation points 0 and 3 were $p<0.05$ against observation points 1 , 2, and 4, showing a significant difference. The effect of blocked sunlight and ground cover is considered to show remarkable results in terms of thermal sensation.

At observation points $0,1,2$, and 4 , the result of testing the homogeneity of the responses of the thermal sensation between Thai females who are thermally adapted to tropical regions and Japanese females who are thermally adapted to temperate regions were $\mathrm{p}>0.10\left(\chi^{2}=2.373, \mathrm{p}=0.668\right),\left(\chi^{2}=2.838, \mathrm{p}=0.585\right),\left(\chi^{2}=1.077, \mathrm{p}=\right.$ $0.783),\left(\chi^{2}=2.795, p=0.593\right)$, respectively, showing no significant difference. However, observation point 3 was $\mathrm{p}<0.05\left(\chi^{2}=8.575, \mathrm{p}=0.036\right)$ showing a significant difference. This is because the "warm" has been shown significant differences in $\mathrm{p}<0.05$ and the number of samples that responded "warm" is small. Observation point 3 east and west faces are covered with a concrete building, the ground surface is covered with concrete pavement, north and south faces are open. Therefore, depending on the positioning, the long-wave thermal radiation by the surface temperature of the building and the ground surface is increased. Moreover, the sample number of subjects that responded to the "warm" of thermal sensation is remarkably small. This is the cause. However, it on the whole was evident that there is no great difference in the psychological response of the thermal sensation between Thai females who are thermally adapted to tropical regions and Japanese females who are thermally adapted to temperate regions.

\subsection{Relationship between Thermal Comfort and Observation Point}

Figure 2 shows the relationship between thermal comfort and the observation points. Observation points 0 and 3 , which have a low sky factor, are values of "comfortable", expressed as percentages that are remarkably high. As with thermal sensation, plants such as trees that block sunlight are considered to show an effect. Then, observation points 2 and 4, which have a high sky factor, are values of "comfortable", expressed as a percentage that is remarkably low. In spaces with nothing to block the sunlight, feelings of discomfort are considered to be more apparent. Also, observation point 1 , which has a high green factor, shows a remarkable percentage value for "comfortable" and "slightly uncomfortable", which is remarkably high. This is considered to show that the observation point 1 was the almost same responses of the observation points 0 and 3. Similar to the indications of thermal sensation, this is considered to show that the influence of visual stimuli such as natural elements including vegetation like greenery [50] [51].

The result of testing the homogeneity of responses was $p<0.01\left(\chi^{2}=105.59\right)$, showing a significant difference. Observation points 0 and 3 were $\mathrm{p}<0.05$ against observation points 1,2 , and 4 , showing a significant difference. Especially, observation point 1 was $\mathrm{p}<0.05$ against observation points 0,2 , 3, and 4, showing a significant difference. The effect of blocked sunlight and ground cover is considered to show remarkable results in terms of thermal comfort.

At each observation point, the result of testing the homogeneity of the responses of the thermal comfort between Thai females who are thermally adapted to tropical regions and Japanese females who are thermally 


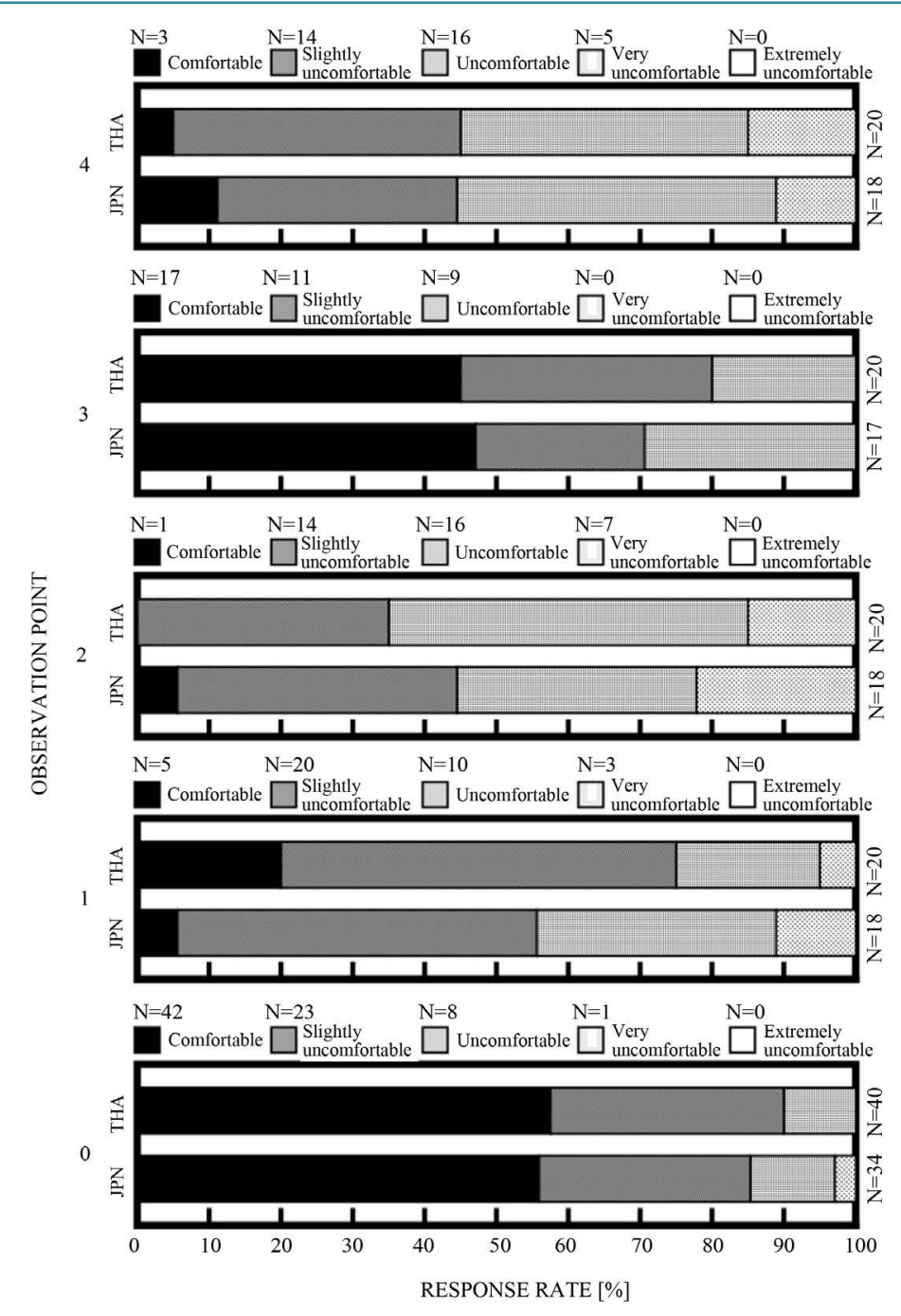

Figure 2. Relationship between thermal comfort and observation point. JPN is a Japanese female. THA is a Thai female.

adapted to temperate regions were $\mathrm{p}>0.10\left(\chi^{2}=1.673, \mathrm{p}=0.643 ; \chi^{2}=2.765, \mathrm{p}=0.429 ; \chi^{2}=2.435, \mathrm{p}=0.487\right.$; $\chi^{2}=0.755, \mathrm{p}=0.686 ; \chi^{2}=0.723, \mathrm{p}=0.868$ ), respectively, showing no significant difference. It was evident that there is no great difference in the psychological response of the thermal comfort between Thai females and Japanese females.

\section{Discussion}

\subsection{Relationship between ETFe and Thermal Sensation}

Figure 3 shows the relationship between ETFe and thermal sensation. A trend was seen in responses on the "hot" side as ETFe increased. The thermal sensation was distributed over a wide range from cool to hot, clearly indicating significant individual differences. Thai thermal sensation compared to the Japanese one has shown a tendency to respond to the extreme thermal sensation to cold side to hot side. However, thermal comfort did not show a large difference between Thai females, who were acclimatized to the tropical region, and Japanese females, who were acclimatized to the temperate region. For ETFe in the range from $35^{\circ} \mathrm{C}-40^{\circ} \mathrm{C}$, responses of thermal sensation were in the range from "slightly cool" to "slightly warm", and a variation was confirmed. The sense of expectation for the degree of comfort in outdoors is low to begin with and they are not judged to be comfortable thermal environments. So it is conceivable that the acceptability raised the neutral temperature that 


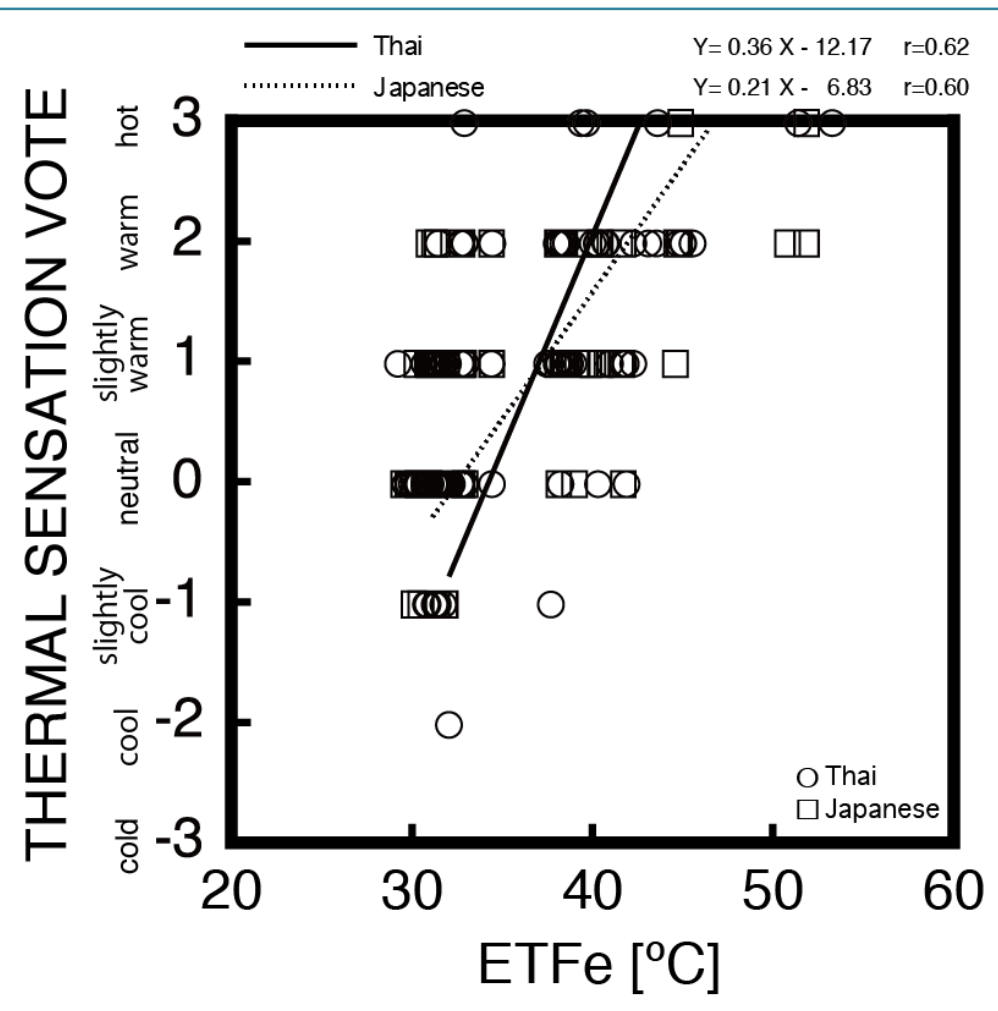

Figure 3. Relationship between ERFe and thermal sensation.

is responded a neither too hot nor too cold even for thermal environment conditions where ETFe was high.

As pointed out by Kurazumi et al. [12], even if a thermal environment is uncomfortable, outdoor spaces in which the place can be selected or viewed according to free will are considered to allow a wider range of thermal environments. Namely, freedom of movement occurs in the test environment, which is thought to generate a large variation in the psychological response in outdoor spaces. Also, outdoor thermal environment factors of short-wave solar radiation, long-wave thermal radiation, and airflow are unstable and asymmetric. These environmental factors have the possibility of contributing to local influences on the body even if the heat balance is equal across the whole body. Horikoshi et al. [53] clarified that directional variations appear due to the influence of local thermal radiation on psychological responses of the body in unstable, asymmetric thermal radiation environments. Kurazumi et al. [54] clarified the existence of parameters for unstable, asymmetric thermal radiation environments in thermal environment indices assessing body influences in unstable, asymmetric thermal radiation environments. A large variation was shown to occur in the physiological response due to the influence of these parameters. Namely, due to not only the psychological responses to thermal actions in outdoor spaces but also the influences of other environmental stimuli, large variations in thermal sensation are considered to occur in outdoor spaces.

On the other hand, in environments with ETFe exceeding $40^{\circ} \mathrm{C}$, a strong trend in responses on the "hot" side was shown. In an environment in which the body is subjected to moderate thermal stimuli, the influence of other environmental stimuli is considered to change the psychological response of the body. However, in an environment with remarkably strong thermal environmental stimuli, the psychological response is considered to become specialized to the thermal environmental stimuli.

By focusing on the regression line, moderate thermal sensations, that is, from slightly cool to slightly warm, respond at an ETFe of from $34.2^{\circ} \mathrm{C}-37.0^{\circ} \mathrm{C}$ on Thai females and at an ETFe of from $32.4^{\circ} \mathrm{C}-37.2^{\circ} \mathrm{C}$ on Japanese females. Japanese females are able to respond to a wider range of thermal environments than the Thai females. An analysis of covariance (ANCOVA) was performed. The result revealed that this relationship was parallelism $($ RMSE $=1.68, \mathrm{~F}(3,209)=1.27, \mathrm{p}=0.261)$ and homogeneous (Welch's t-test, RMSE $=2.83, \mathrm{t}(300)=$ $2.18, \mathrm{p}=0.030$ ). It was evident that there is no great difference in the psychological response of the thermal sensation between Thai females and Japanese females. 


\subsection{Relationship between ETFe and Thermal Comfort}

Figure 4 shows the relationship between ETFe and thermal comfort. The trend of as ETFe increases, the "uncomfortable" strength rises is shown. The thermal comfort was distributed over a wide range from slightly uncomfortable to very uncomfortable, again clearly indicating significant individual differences. Thermal comfort did not show a large difference between Thai females and Japanese females. In the range of ETFe up to $40^{\circ} \mathrm{C}$, responses of thermal comfort in the range from "comfortable" to "uncomfortable" are shown.

Similar to the indications of Kurazumi et al. [12], the outdoor thermal environmental factors of short-wave solar radiation, long-wave thermal radiation, and airflow are unstable and asymmetric, and the influence of these environmental factor parameters is considered to cause variations in physiological responses. The body can experience discomfort depending on variations in environmental factors, and those experiences are thought to induce relative comfort. Therefore, even for other environmental factors, variations affecting reductions in thermal actions are thought to become variation factors of discomfort.

Looking at the regression line, an ETFe thought to be responded as "comfortable" is $31.1^{\circ} \mathrm{C}$ for Thai females and at an ETFe of from $31.5^{\circ} \mathrm{C}$ for Japanese females. Also, an ETFe thought to be responded as "uncomfortable" is $38.2^{\circ} \mathrm{C}$ for Thai females and at an ETFe of from $37.7^{\circ} \mathrm{C}$ for Japanese females. As pointed out by Hoöppe [31], Nikolopoulou and Steemers [16], Spagnolo and de Dear [32], Nakano and Tanabe [33], Ahmed [34], Oliveira and Andrade [14], Lin and Matzarakis [35], Cheng et al. [36], and Kurazumi et al. [12], high air temperatures are common in the summer season. Environmental stimuli in outdoor spaces have the possibility of arousing physiological responses that differ from those in indoor spaces. Then, the sense of expectation of the degree of comfort in the outdoors is low to begin with, and they are not judged to be comfortable thermal environments, then it is conceivable that the acceptability raised the thermal environment conditions, even for ETFe was high.

An analysis of covariance (ANCOVA) was performed. The result revealed that this relationship was parallelism (RMSE $=0.772, \mathrm{~F}(3,221)=0.633, \mathrm{p}=0.427)$ and homogeneous (Welch's $\mathrm{t}$-test, $\mathrm{RMSE}=0.919, \mathrm{t}(223)=$ $0.763, p=0.446$ ). It was evident that there is no great difference in the psychological response of thermal comfort between Thai females Japanese females.

\subsection{Relationship between Thermal Sensation and Thermal Comfort}

Figure 5 shows the relationship between thermal sensation and thermal comfort. The strength of "uncomfortable" thermal comfort shows an increasing trend that follows the rising level of thermal sensation. The psychological

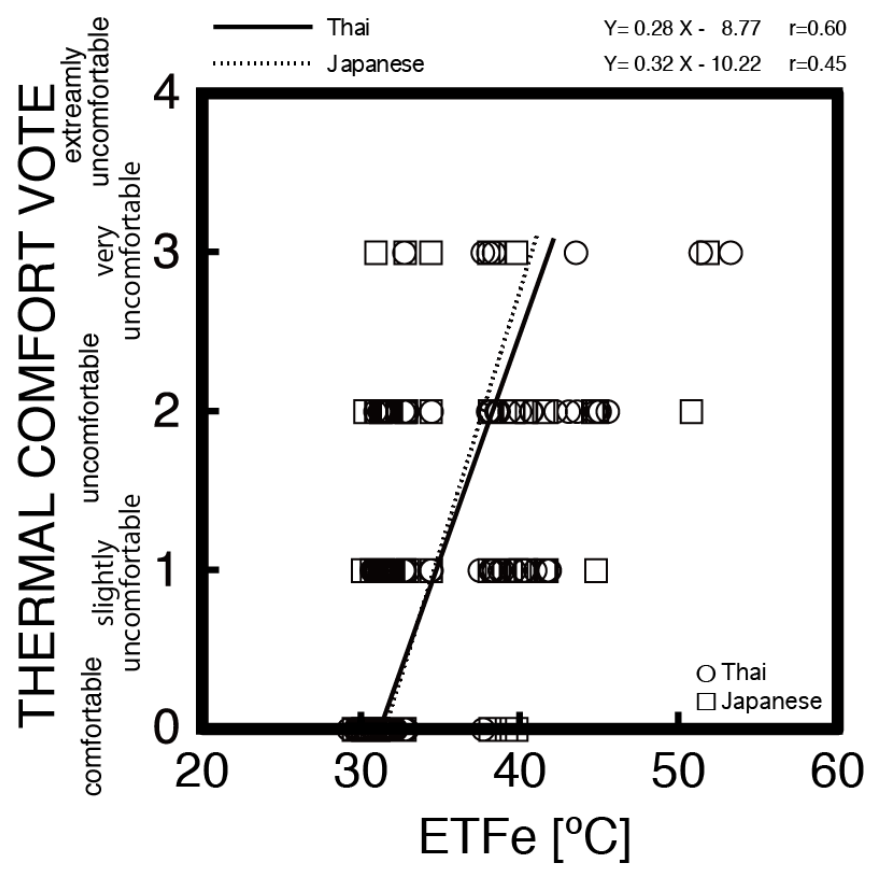

Figure 4. Relationship between ERFe and thermal comfort. 

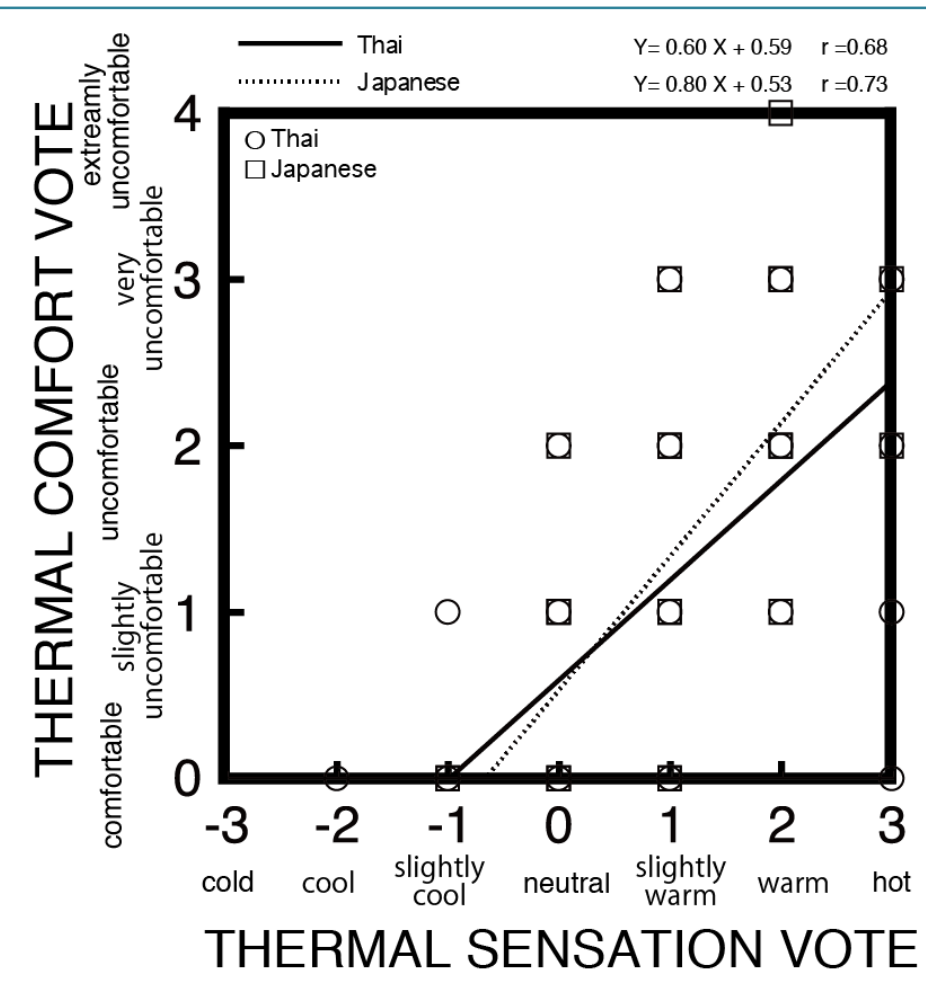

Figure 5. Relationship between thermal sensation and thermal comfort.

responses demonstrate significant individual differences. However, based on the distribution density in ranges, results suggest that thermal sense did not show a large difference between Thai females and Japanese females. Many of the thermal sensation responses of "comfortable" are in the range from "cool" to "slightly warm".

Looking at the regression line, the most "comfortable" side of the thermal sensation is shown to be in the range of "slightly cool" to "neutral", at -0.98 on Thai females and at -0.66 on Japanese females. Kurazumi et al. [11] clarified that the most comfortable response is shown to be in the range from "slightly cool" to "neutral" for the target of Thai people in the dry season. This study of the rainy season shows the same tendency as dry season experiments of Kurazumi et al. [11]. From the most "comfortable" side thermal sensation response value, the ETFe of $31.4^{\circ} \mathrm{C}$ for the Thai females and $29.3^{\circ} \mathrm{C}$ for Japanese females was calculated.

An analysis of covariance (ANCOVA) was performed. The result revealed that this relationship was parallelism $(\mathrm{RMSE}=0.651, \mathrm{~F}(3,221)=0.899, \mathrm{p}=0.344)$ and homogeneous (Welch's t-test, $\mathrm{RMSE}=0.919, \mathrm{t}(223)=$ $0.763, p=0.446$ ). It was evident that there is no great difference in the psychological response of thermal sense between Thai females and Japanese females.

\section{Conclusions}

By evaluating the influence of the outdoor thermal environment on the human body using the thermal environment evaluation index ETFe based on the body heat balance equations of the outdoor environment, it has been made clear that there is no great difference in the psychological response of thermal sense between Thai people, who are thermally adapted to tropical regions, and Japanese people, who are thermally adapted to temperate regions. Also, the ETFe is kept at around $35^{\circ} \mathrm{C}$ in a moderate thermal environment, but it is clear that an environment with an ETFe exceeding $40^{\circ} \mathrm{C}$ is not acceptable. The knowledge gained from this experiment is as follows:

1) Up to an ETFe of $35^{\circ} \mathrm{C}$, responses of thermal sensation were shown in the range from "cool" to "warm". However, in environments with ETFe exceeding $40^{\circ} \mathrm{C}$, a strong trend in responses on the "hot" side was shown. In an environment in which the body is subjected to moderate thermal stimuli, even if a thermal environment is uncomfortable, outdoor spaces in which the place can be selected or viewed according to free will are considered to allow a wider range of thermal environments; however, in an environment with remarkably strong thermal environmental stimuli, the psychological response is shown to become specialized to the thermal envi- 
ronmental stimuli.

2) The moderate thermal sensations, that is, from "slightly cool" to "slightly warm", respond at an ETFe of $34.2^{\circ} \mathrm{C}-37.0^{\circ} \mathrm{C}$ on Thai females and at an ETFe of $32.4^{\circ} \mathrm{C}-37.2^{\circ} \mathrm{C}$ on Japanese females. Japanese females are able to respond to a wider range of thermal environments than the Thai females.

3) An ETFe thought to be "comfortable" is $31.1^{\circ} \mathrm{C}$ for Thai females and an ETFe of $31.5^{\circ} \mathrm{C}$ for Japanese females. Also, an ETFe thought to be "uncomfortable" is $38.2^{\circ} \mathrm{C}$ for Thai females and an ETFe of $37.7^{\circ} \mathrm{C}$ for Japanese females. The sense of expectation for the degree of comfort in outdoors is low to begin with, and they are not judged to be comfortable thermal environments, then it is conceivable that the acceptability raised the thermal environment conditions, even if ETFe was high.

4) The most "comfortable" side of the thermal sensation is shown to be in the range from "slightly cool" to "neutral". From the most "comfortable" side thermal sensation response value, the ETFe of $31.4^{\circ} \mathrm{C}$ for Thai females and $29.3^{\circ} \mathrm{C}$ for Japanese females was calculated.

\section{Acknowledgements}

We would like to express our sincerest gratitude to the study subjects who participated in the present study.

\section{References}

[1] IPCC Working Group I Contribution to AR5 (2014) Summary for Policymakers of Climate Change 2013: The Physical Science Basis. http://www.climatechange2013.org/images/report/WG1AR5_SPM_FINAL.pdf

[2] Edwards, C.L., Fillingim, R.B. and Keefe, F. (2001) Race, Ethnicity and Pain (Review). Pain, 94, 133-137. http://dx.doi.org/10.1016/S0304-3959(01)00408-0

[3] Watson, P.J., Khalid Latif, R. and Rowbotham, D.J. (2005) Ethnic Differences in Thermal Pain Responses: A Comparison of South Asian and White British Healthy Males. Pain, 118, 194-200. http://dx.doi.org/10.1016/j.pain.2005.08.010

[4] Taylor, N.A.S. (2006) Ethnic Differences in Thermoregulation: Genotypic versus Phenotypic Heat Adaptation. Journal of Thermal Biology, 31, 90-104. http://dx.doi.org/10.1016/j.jtherbio.2005.11.007

[5] Saat, M.I. and Tochihara, Y. (2008) Heat Adaptation of Tropic-Dwelling People. Journal of Human-Environment System, 11, 7-12. http://dx.doi.org/10.1618/jhes.11.7

[6] Lee, J.Y., Saat, M., Chou, C., Hashiguchi, N., Wijayanto, T., Wakabayashi, H. and Tochihara, Y. (2010) Cutaneous Warm and Cool Sensation Thresholds and the Inter-Threshold Zone in Malaysian and Japanese Males. Journal of Thermal Biology, 35, 70-76. http://dx.doi.org/10.1016/j.jtherbio.2009.11.002

[7] Lee, J.Y., Wakabayashi, H. and Wijayanto, T. (2011) Ethnic Differences in Thermoregulatory Responses during Resting, Passive and Active Heating: Application of Werner's Adaptation Model. European Journal of Applied Physiology, 111, 2895-2905. http://dx.doi.org/10.1007/s00421-011-1912-5

[8] Wijayanto, T., Wakabayashi, H., Lee, J.Y., Hashiguchi, N., Saat, M. and Tochihara, Y. (2011) Comparison of Thermoregulatory Responses to Heat between Malaysian and Japanese Males during Leg Immersion. International Journal of Biometeorology, 55, 491-500. http://dx.doi.org/10.1007/s00484-010-0358-5

[9] Wakabayashi, H., Wijayanto, T., Lee, J.Y., Hashiguchi, N., Saat, M. and Tochihara, Y. (2011) Comparison of Heat Dissipation Response between Malaysian and Japanese Males during Exercise in Humid Heat Stress. International Journal of Biometeorology, 55, 509-517. http://dx.doi.org/10.1007/s00484-010-0374-5

[10] Tochihara, Y., Lee, J.Y., Wakabayashi, H., Wijayanto, T., Bakri, I. and Parsons, K. (2012) The Use of Language to Express Thermal Sensation Suggests Heat Acclimatization by Indonesian People. International Journal of Biometeorology, 56, 1055-1064. http://dx.doi.org/10.1007/s00484-011-0519-1

[11] Kurazumi, Y., Ishii, J., Fukagawa, K. and Aruninta, A. (2015) The Influence of Tropical Urban Climate upon the Human Body. International Joint-Conference of SENVAR-iNTA-AVAN 2015 (SIA 2015), Johor, 24-26 November 2015, 105-114.

[12] Kurazumi, Y., Ishii, J., Kondo, E., Fukagawa, K., Bolashikov, Z.D., Sakoi, T., Tsuchikawa, T., Matsubara, N. and Horikoshi, T. (2013) The Influence of Outdoor Thermal Environment on Young Japanese Female. International Journal of Biometeorology, 58, 963-974. http://dx.doi.org/10.1007/s00484-013-0681-8

[13] Givoni, B., Noguchi, M., Saaroni, H., Pochter, O., Yaacov, Y., Feller, N. and Becker, S. (2003) Outdoor Comfort Research Issues. Energy and Buildings, 35, 77-86. http://dx.doi.org/10.1016/S0378-7788(02)00082-8

[14] Oliveira, S. and Andrade, H. (2007) An Initial Assessment of the Bioclimatic Comfort in an Outdoor Public Space in Lisbon. International Journal of Biometeorology, 52, 69-84. http://dx.doi.org/10.1007/s00484-007-0100-0 
[15] Eliasson, I., Knez, I., Westerberg, U., Thorsson, S. and Lindberg, F. (2007) Climate and Behaviour in a Nordic City. Landscape and Urban Planning, 82, 72-84. http://dx.doi.org/10.1016/j.landurbplan.2007.01.020

[16] Nikolopoulou, M. and Steemers, K. (2003) Thermal Comfort and Psychological Adaptation as a Guide for Designing Urban Spaces. Energy and Buildings, 35, 95-101. http://dx.doi.org/10.1016/S0378-7788(02)00084-1

[17] Nikolopoulou, M. and Lykoudis, S. (2006) Thermal Comfort in Outdoor Urban Spaces: Analysis across Different European Countries. Building and Environment, 41, 1455-1470. http://dx.doi.org/10.1016/j.buildenv.2005.05.031

[18] Ishii, J., Horikoshi, T., Kurazumi, Y., Nagano, K. and Fukagawa, K. (2008) A Field Survey of Thermal Comfort in Outdoor Space. ICB2008 18th International Congress of Biometeorology, Tokyo, 22-16 September 2008, 1-4.

[19] Kurazumi, Y., Tsuchikawa, T., Matsubara, N., Kondo, E. and Horikoshi, T. (2011) Evaluation of Enhanced Conduction-Corrected Modified Effective Temperature ETFe as the Outdoor Thermal Environment Evaluation Index. Energy and Buildings, 43, 2925-2937. http://dx.doi.org/10.1016/j.enbuild.2011.07.019

[20] Kurazumi, Y., Kondo, E., Ishii, J., Sakoi, T., Fukagawa, K., Bolashikov, Z.D., Tsuchikawa, T., Matsubara, N. and Horikoshi, T. (2013) Effect of the Environmental Stimuli upon the Human Body in Winter Outdoor Thermal Environment. Journal of Environmental and Public Health, Article ID 418742, 1-10. http://dx.doi.org/10.1155/2013/418742

[21] National Institute for Environmental Studies (2015) Bulletin Report on Heatstroke Patients. http://www.nies.go.jp/health/HeatStroke/spot/english/index.html

[22] Humphreys, M. (1976) Field Studies of Thermal Comfort Compared and Applied. Building Services Engineer, 44, 5-27.

[23] Brager, G.S. and deDear, R.J. (1998) Thermal Adaptation in the Build Environment: A Literature Review. Energy and Buildings, 27, 83-96. http://dx.doi.org/10.1016/S0378-7788(97)00053-4

[24] deDear, R.J. and Brager, G.S. (1998) Developing an Adaptive Model of Thermal Comfort and Preference. ASHRAE Transactions, 104, 145-167.

[25] Nikolopoulou, M., Baker, N. and Steemers, K. (2001) Thermal Comfort in Outdoor urban Spaces: Understanding the Human Parameter. Solar Energy, 70, 227-235. http://dx.doi.org/10.1016/S0038-092X(00)00093-1

[26] Knez, I. and Thorsson, S. (2006) Influence of Culture and Environmental Attitude on Thermal, Emotional and Perceptual Evaluations of a Square. International Journal of Biometeorology, 50, 258-268. http://dx.doi.org/10.1007/s00484-006-0024-0

[27] Kántor, N. and Unger, J. (2011) Benefits and Opportunities of Adopting GIS in Thermal Comfort Studies in Resting places: An Urban Park as an Example. Landscape and Urban Planning, 98, 36-46. http://dx.doi.org/10.1016/j.landurbplan.2010.07.008

[28] Kurazumi, Y., Matsubara, N., Tsuchikawa, T., Kondo, E., Ishii, J., Fukagawa, K., Ando, Y., Yamato, Y., Tobita, K. and Horikoshi, T. (2011) Psychological Effects of the Environmental Stimuli on Thermal Sense in Outdoor Spaces. Japanese Journal of Biometeorology, 48, 129-144.

[29] Kurazumi, Y., Tsuchikawa, T., Kondo, E., Ishii, J., Fukagawa, K., Yamato, Y., Tobita, K., Ando, Y., Matsubara, N. and Horikoshi, T. (2012) Thermal Comfort Zone in Outdoor Environment. Journal of Human and Living Environment, 19, 115-127.

[30] Kurazumi, Y., Fukagawa, K., Yamato, Y., Tobita, K., Kondo, E., Tsuchikawa, T., Horikoshi, T. and Matsubara, N. (2011) Enhanced Conduction-Corrected Modified Effective Temperature as the Outdoor Thermal Environment Evaluation Index upon the Human Body. Building and Environment, 46, 12-21. http://dx.doi.org/10.1016/j.buildenv.2010.06.012

[31] Höppe, P. (2002) Different Aspects of Assessing Indoor and Outdoor Thermal Comfort. Energy and Buildings, 34, 661-665. http://dx.doi.org/10.1016/S0378-7788(02)00017-8

[32] Spagnolo, J. and deDear, R.J. (2003) A Field Study of Thermal Comfort in Outdoor and Semi-Outdoor Environments in Subtropical Sydney Australia. Building and Environment, 38, 721-738. http://dx.doi.org/10.1016/S0360-1323(02)00209-3

[33] Nakano, J. and Tanabe, S. (2004) Thermal Comfort and Adaptation in Semi-Outdoor Environments. ASHRAE Transactions, 110, 543-553.

[34] Ahmed, K.S. (2003) Comfort in Urban Spaces: Defining the Boundaries of Outdoor Thermal Comfort for the Tropical Urban Environments. Energy and Buildings, 35, 103-110. http://dx.doi.org/10.1016/S0378-7788(02)00085-3

[35] Lin, T.P. and Matzarakis, A. (2008) Tourism Climate and Thermal Comfort in Sun Moon Lake, Taiwan. International Journal of Biometeorology, 52, 281-290. http://dx.doi.org/10.1007/s00484-007-0122-7

[36] Cheng, M., Lo, J. and Chen, S. (2011) Investigation of the Effect of Climatic Adaptation on Users’ Thermal Comfort Requirement in Outdoor Space. International Journal of the Physical Sciences, 6, 6042-6052.

[37] World Medical Association (2015). http://www.wma.net/en/30publications/10policies/b3/index.html 
[38] Hanada, K., Mihira, K. and Ohhata, K. (1981) Studies on the Thermal Resistance of Women’s Underwear. Journal of the Japan Research Association for Textile End-Use, 22, 430-437.

[39] Kurazumi, Y., Tsuchikawa, T., Torii, T., Kakutani, K., Matsubara, N. and Horikoshi, T. (2004) Weighting Coefficients for Calculating Mean Skin Temperature When Considering Convective Heat Transfer Areas. Journal of the HumanEnvironmental System, 7, 19-28. http://dx.doi.org/10.1618/jhes.7.19

[40] Kurazumi, Y., Matsubara, N., Furukawa, N., Fujiwara, M., Ue, A., Ueki, Y., Nagai, H. and Yamamoto, S. (1998) Japanese Weighting Coefficients for Calculating Mean Skin Temperature in Relation to Posture. Japanese Journal of Biometeorology, 35, 121-132.

[41] Kurazumi, Y., Tsuchikawa, T., Matsubara, N. and Horikoshi, T. (2008) Effect of Posture on the Heat Transfer Areas of the Human Body. Building and Environment, 43, 1555-1565. http://dx.doi.org/10.1016/j.buildenv.2007.09.001

[42] Miyamoto, S., Horikoshi, T. and Hirokawa, Y. (1998) Projected Area Factors of the Human Body at Standing Posture under Different Clothing Conditions. Journal of Architecture, Planning and Environmental Engineering, Transactions of $A I J, 513,47-52$.

[43] Kuwabara, K., Mochida, T., Kondo, M. and Matsunaga, K. (2001) Measurement of Man’s Convective Heat Transfer Coefficient by Using a Thermal Manikin in the Middle Wind Velocity Region. Journal of Human and Living Environment, 8, 27-32.

[44] Hendler, E., Crosbie, R. and Hardy, J.D. (1958) Measurement of Heating of the Skin during Exposure to Infrared Radiation. Journal of Applied Physiology, 12, 177-185.

[45] Elam, R., Goodwin, D.W. and Lloyd, W.K. (1963) Optical Properties of the Human Epidermis. Nature, 198, 10011002. http://dx.doi.org/10.1038/1981001a0

[46] VDI (2008) VDI 3787-2, Environmental Meteorology-Methods for the Human Biometeorological Evaluation of Climate and Air Quality for Urban and Regional Planning at Regional Level. Part 1: Climate. Beuth, Berlin.

[47] Watanabe, S., Horikoshi, T. and Tomita, A. (2010) Measurement of Solar Radiation Absorptance of Clothed Human Body in Outdoor. Japanese Journal of Biometeorology, 47, 165-173.

[48] Kurazumi, Y., Sakoi, T., Tsuchikawa, T., Fukagawa, K., Bolashikov, Z.D. and Horikoshi, T. (2014) Behavioral Thermoregulation Model for Evaluation of Outdoor Thermal Environment. Journal of Ergonomics, 4, 125.

[49] Kuwasawa, Y., Saito, M., Kamata, M. and Chida, Y. (1999) Effects of Fluctuating Air Movement on Thermal Comfort. Journal of Architecture, Planning and Environmental Engineering, Transactions of AIJ, 526, 37-42.

[50] Fukagawa, K., Kurazumi, Y., Yamato, Y., Tobita, K., Hase, H., Han, S., Oishi, H. and Cao, Z. (2010) The Effect of Visual Stimulus on Thermal Comfort: Analysis of the Visual Factor by Experiment. Proceedings of the 7th International Cost Engineering Council World Congress \& The 14th Pacific Association of Quantity Surveyors Congress, Singapore, 23-27 July 2010, 1-10.

[51] Kurazumi, Y., Fukagawa, K., Kondo, E. and Sakoi, T. (2014) Effects of Visual Stimuli upon Thermal Sense under Air Conditioning in Summer. Journal of Ergonomics, 4, Article ID: 1000129.

[52] Kurazumi, Y., Tsuchikawa, T., Kondo, E., Horikoshi, T. and Matsubara, N. (2010) Conduction-Corrected Modified Effective Temperature as the Indices of Combined and Separate Effect of Environmental Factors on Sensational Temperature. Energy and Buildings, 42, 441-448. http://dx.doi.org/10.1016/j.enbuild.2009.10.012

[53] Horikoshi, T., Kurazumi, Y., Hirayama, K., Tsuchikawa, T. and Kobayashi, Y. (1989) Indication of the Effect of Asymmetric Thermal Radiation of the Human Physiological and Psychological Responses. The 2nd World Congress on Heating, Ventilating, Refrigerating and Air Conditioning-CLIMA 2000, III, Sarajevo, Yugoslavia, 27 August-1 September 1989, 188-193.

[54] Kurazumi, Y., Horikoshi, T., Hirayama, K., Tsuchikawa, T. and Kobayashi, Y. (1993) The Influence of Asymmetric and Uneven Thermal Radiation Environments upon the Human Body: In the Case of Constant Operative Temperature. Journal of Architecture, Planning and Environmental Engineering, Transactions of AIJ, 447, 17-26. 